\title{
Considerations on the selection of rockbolts for rapid and secure mine development
}

\author{
F. Charette DSI Mining, Canada
}

\begin{abstract}
This paper presents a comparison of various rockbolt systems based on the rapidity of advance, cost of advance, opportunities for mechanisation, as well as immediate and long-term roof stability. The main rockbolt types analysed are the traditional shell expansion rockbolt, split tube bolts, resin grouted rebars and water expanded friction rockbolts. Typical productivity of the abovementioned bolting systems, based on actual field measurements, is reviewed and compared. Advantages and problems related to mechanisation are discussed and proposals for improvements are made.
\end{abstract}

\section{Introduction}

Rockbolting systems provide the bulk of reinforcement in underground mining operations. However, their specific applicability should be reviewed based on their mechanical performance, i.e. how well they keep an excavation stable and safe. Furthermore, some systems, although more expensive with the material used, can provide a better overall performance, as is the case with fully grouted bars and water expanded rockbolts. In addition, the use of dedicated bolting machines can increase the performance of rockbolting by up to $50 \%$ with a drastic reduction in risk of accidents caused by ground falls.

Best results are achieved when the short and long-term requirements are well defined and ground conditions are known or reasonably well defined. Failure to understand the behaviour of the mine as an engineering structure will lead to unsatisfactory rock reinforcement, especially in the later years of the operation. As the structure ages, the response to rock stress changes becomes more important and the rock reinforcement has to be designed accordingly.

\section{Bolts description}

\subsection{Water expanded rockbolts}

Water expanded rockbolts (WEB) type rockbolts are made from low carbon steel that have a relatively low strain hardening rate. Since mechanical properties of the steel will vary slightly between manufacturers, laboratory and field tests are necessary to assess the overall performance of the rockbolt. However, in essence, there are two main types of WEB, one being a basic steel WEB, and the other a heat treated yielding WEB. These can be available in regular strength (10-12 t) and high strength (20-24 t). Regular strength bolts provide an anchorage capacity varying from $10-25 \mathrm{t} / \mathrm{m}$ and since this friction value is constant all along the bolt, the reinforcement it creates is important. The installation method is simple, but necessitates the use of a high pressure water pump to expand the bolt in the borehole. Specific rules for the inflation process must be followed to assure that the tubes are properly expanded. Once this is confirmed, the bolt installation is always secure and the system can be considered to be a full proof installation system.

\subsection{Mechanical expansion anchor rockbolts}

Expansion shell rockbolts are the least expensive of the rockbolts used in the mining industry. With a high volume of sales, the overall material cost of shell bolts is kept low. Most bar and expansion shell combinations provide a good ratio of bolt strength to overall cost. Also, the installation method is simple, fast and the costs associated with it are very low. However, in excavations that do not exhibit large deformations, the expansion shell anchor tends to work loose with every blast in the vicinity. Unless the 
walls and roof show a reasonable amount of convergence, bolt tension decreases with blast vibrations and the bolts need to be re-tightened regularly in order to stay effective. Failure to do so will result in rehabilitation works that are costly and delay the operation.

\subsection{Split tube friction bolt}

These rockbolts are moderately expensive, but their installation is also very simple and fast, and they do not need any special equipment, except a dolly fitting on the shank of the drilling equipment. The split friction tube provides a moderate support pressure and the anchorage capacity is also limited. In blocky ground, the tube gets locked in by the shear along joints and the reinforcement and support capacity is then increased. The tube is not very stiff, but in compressive stress conditions it does adapt to the offsets caused by block movements and provides a reasonable anchorage and reinforcement. In rock mass relaxation, however, the tube may loose its friction effect and is especially affected by relaxation with small convergence, where single blocks may become free.

\subsection{Grouted rebars}

Reinforcement bars are a very effective means to reinforce the rock mass. However, the installation must be performed by very skilled personnel in order to assure that the grout material, and especially in case of resin rebars, is well mixed and covers the entire length of the bar while filling the hole around the bar. Resin loss is usually at least $15 \%$ of the resin used, but can reach higher values if stock management is deficient or if the installation method is not adequate. Installation is also slower than the expansion shell bolt and the split tube, mostly because of the resin cartridge insertion. This time can be shortened by using a pneumatic resin cartridge insertion device, but it is still an additional operation between hole drilling and bolt insertion in the borehole.

\section{Basis of rockbolt selection}

The prime consideration of any reinforcement is to efficiently reinforce and support the rock mass. Priority is then given to choosing a rockbolt type, length and pattern that will assure the stability of the excavation. These engineering processes have been summarised by Hoek et al. (1995), Hutchinson and Diederichs (1996), Diederichs et al. (1998) and Barton et al. (1974), among many others. Limit equilibrium methods, for example, can provide the required tensile capacity of the reinforcing elements. Numerical modelling (FLAC, PHASES, etc.) can further assist in determining the required tensile, shear, anchorage and elongation capacity of those units. Suppliers provide accurate data on the tensile and elongation properties of their products and the engineer can use these values to design the support system.

As the mechanical requirements must be met first, only those bolts that pass the engineering criteria should be considered as suitable for the support system. However, once the basic mechanical properties have been established, other parameters will need to be met for a given rockbolting system to be safe and cost efficient. Of those parameters, the bolting costs and the corrosion resistance are the most important. While the cost of rockbolting is easily recognised as an important parameter in the choice of a bolting system, it should never supersede the technical requirements. The effect of the corrosion resistance is a more subtle issue; for a short-term excavation the life span of a rockbolt is not critical, but once an excavation has to stand up for a longer period of time, the reinforcement must be able to safely support the roof and walls for as long as the engineer has planned it. A simple list proposed to evaluate rockbolt type based on the critical design criteria:

- Tensile/yield load.

- Displacement capability.

- Anchoring capacity.

- Shear load and displacement.

- Energy damping.

- Corrosion resistance.

- Cost.

- Ease of quality control. 


\subsection{Mechanical properties}

The first two critical engineering factors of the rockbolt selection are the load and anchorage capacities. The load capacity is typically taken as the tensile strength of the rockbolt, or its anchorage load limit (for expansion shell and split tube bolt). When using split tube bolts to support the roof of an excavation, the engineer must understand that, unless shearing occurs in the roof that locks in the tube, the available anchorage load diminishes linearly with the distance to the collar, as the collar load capacity is the sum of all shear forces developed along the bolt, and this value is less than the tensile strength of the steel. When used in walls, the split tube is usually perfectly adequate in strength and ease of installation, and can be a very economical substitute to other bolt types. Table 1 provides an overview of typical anchorage capacity of different rockbolts, for a medium-hard rock and for soft or broken ground.

Table 1 Typical anchoring capacity of common reinforcement $(t)$

\begin{tabular}{lccc}
\hline & $\begin{array}{c}\text { Medium-Hard } \\
\text { Rock }\end{array}$ & Soft Rock & $\begin{array}{c}\text { Broken Rock and Low } \\
\text { Confinement }\end{array}$ \\
\hline Expansion anchor & $8-10 \mathrm{t}$ & $5-7 \mathrm{t}$ & $5-7 \mathrm{t}$ \\
Split tube 2.4 m & $4-8 \mathrm{t}$ & $3-6 \mathrm{t}$ & $3-8 \mathrm{t}$ \\
Grouted rebar 2.4 m & $30-40 \mathrm{t} / \mathrm{m}$ & $15-30 \mathrm{t} / \mathrm{m}$ & $10-30 \mathrm{t} / \mathrm{m}$ \\
Water expanded tube 2.4 m & $16-25 \mathrm{t} / \mathrm{m}$ & $10-16 \mathrm{t} / \mathrm{m}$ & $10-20 \mathrm{t} / \mathrm{m}$ \\
Cable bolt plain strand & $20-35 \mathrm{t} / \mathrm{m}$ & $10-30 \mathrm{t} / \mathrm{m}$ & $5-20 \mathrm{t} / \mathrm{m}$ \\
Cable bolt modified strand & $75-90 \mathrm{t} / \mathrm{m}$ & $60-80 \mathrm{t} / \mathrm{m}$ & \\
\hline
\end{tabular}

Shear strength is a design parameter that is often not well understood. Research provides useful insight on shear behaviour (Figure 1), that shows shear test results in simulated rock medium: one can see a reduction of shear load with increasing strength of the borehole material — as the rock gets harder and more massive, the bolt shear resistance tends to a value of approximately $75 \%$ of the tensile load of the bolt. Also, it is not always the strength that is the limiting parameter, but rather the deformation capability. As the rock mass is harder and more confined by stress, the deformability of most rockbolts will diminish; water expanded tubes are the most sensitive to this situation.

Once the static loading capacities are confirmed, it may be necessary to review the capability of the rockbolt to sustain dynamic events. Many mining operations may not be subject to serious seismic events during their early life, even when they deal with hard to very hard rocks, high extraction rates, drifting and stoping at depth, and the presence of major geological structures. However, mines that are in the process of mining remnant pillars, for example, are at a higher risk of dynamic activity than new mines, because of higher localised stresses and the lower general stiffness of the mine structure that may lead to more significant release of strain energy.

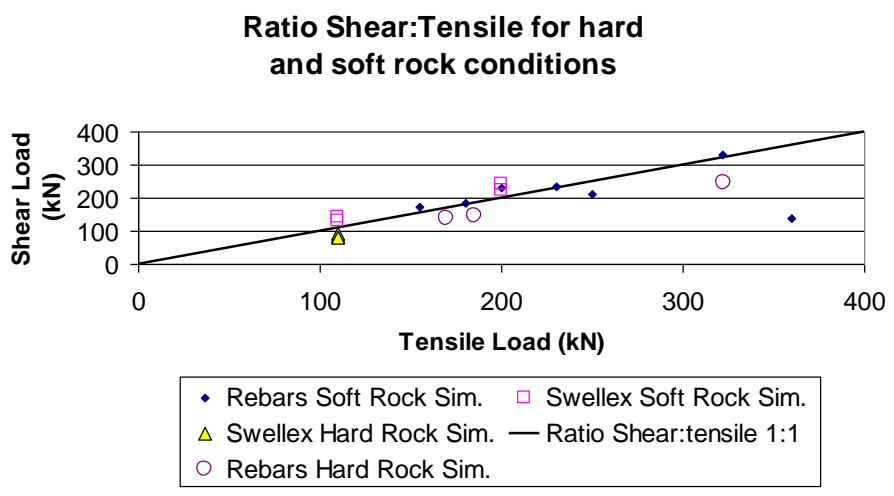

Figure 1 Results of laboratory shear tests on rockbolts 


\subsection{Loading conditions}

One constant in a mining environment is change. Even in relatively isolated structures like ramps and workshops, the stress tensor may experience serious changes during the life of the mine. The design engineer must take these changes into consideration and attempt to predict the worst stages for the reinforcement, as well as the most drastic changes. Failure to do so can result in a reinforcement system that works very well at the initial stage of operation, but is totally overwhelmed later in time. However, when those changes in conditions are defined, even roughly, additional support can be added to compensate the higher demand put on the system at a later date. This methodology has the advantage of providing a very high development rate at the beginning, without overlooking the necessity to support more heavily later. Figure 2 shows a situation where the pattern reinforcement did perform extremely well for years. Eventually, the energy release of the rock mass exceeded the capacity of the system and additional reinforcement and support, namely cables and shotcrete, had to be installed to complement the existing system and the increased demands placed on it.

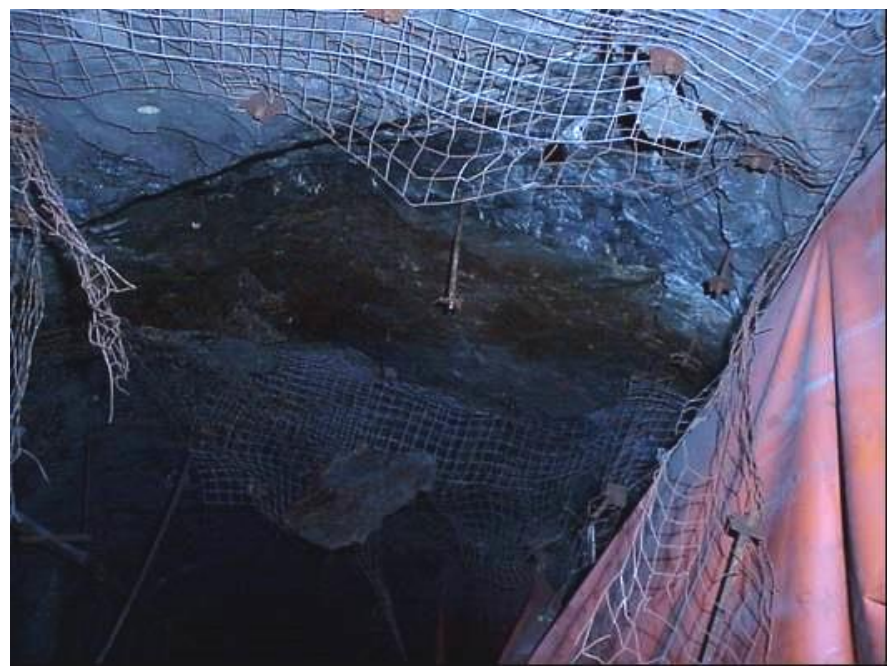

Figure 2 Roof failure in access drift, caused by mining in the upper levels
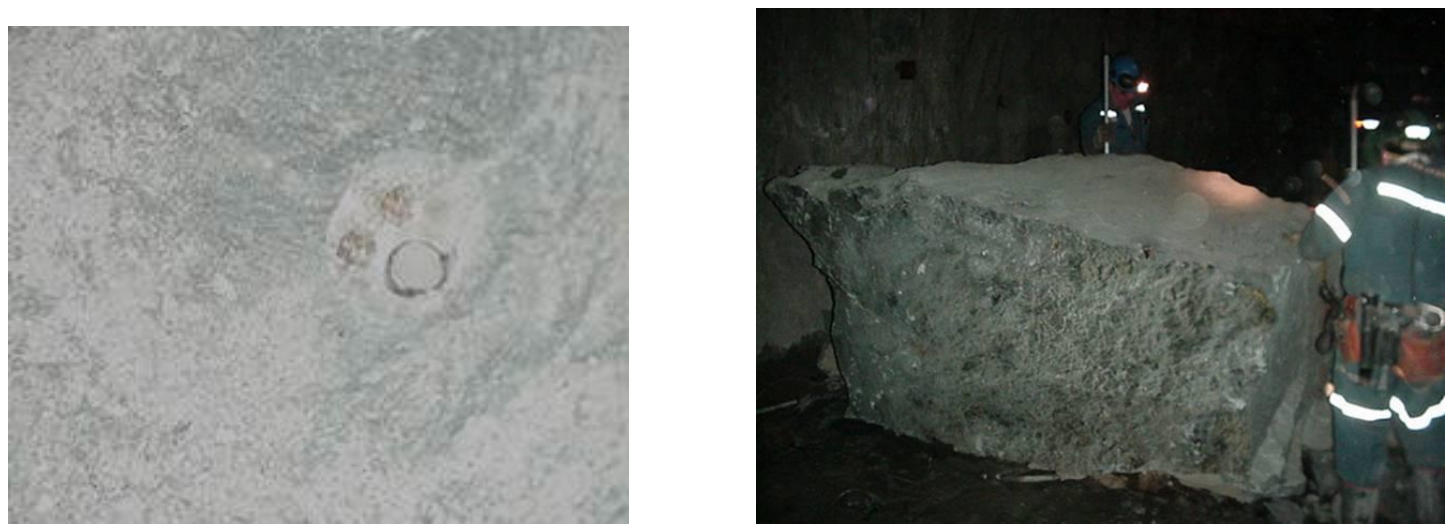

Figure 3 Dynamic event that damaged roof support and lead to localised roof failure

The ground control engineer must also be trained to evaluate the fundamental cause of rock failure, in order to apply an adequate solution. Figures 3 and 4 are examples of ground falls that are caused by localised seismic events. In both cases, the reinforcement was unable to maintain the roof stable following the energy release. In the case of Figure 3 the block that fell, located close to a geological contact between rocks of very different deformation modulus, had a safety factor against gravity loading of more than 16 . In Figure 4 , the very brittle rock failed when parallel advance of excavation generated excessive stress along subhorizontal joints. The weights of the blocks were around $1 \mathrm{t} / \mathrm{m}^{2}$, well below the static capacity of the installed rockbolts (Rebars and Swellex), but the mode of failure was a dynamic one. Static factor of safety was well above eight. Both cases were located in metal mines, at a depth of about $400 \mathrm{~m}$, with a high production tonnage. In 
both cases, it was not expected that the development around existing excavations would be affected so intensely by the stress re-distribution, and no contingency was put in place. Very strong rock and presence of geological structures should always be a clue of a potential dynamic problem in high production mining methods, even at moderate depth.

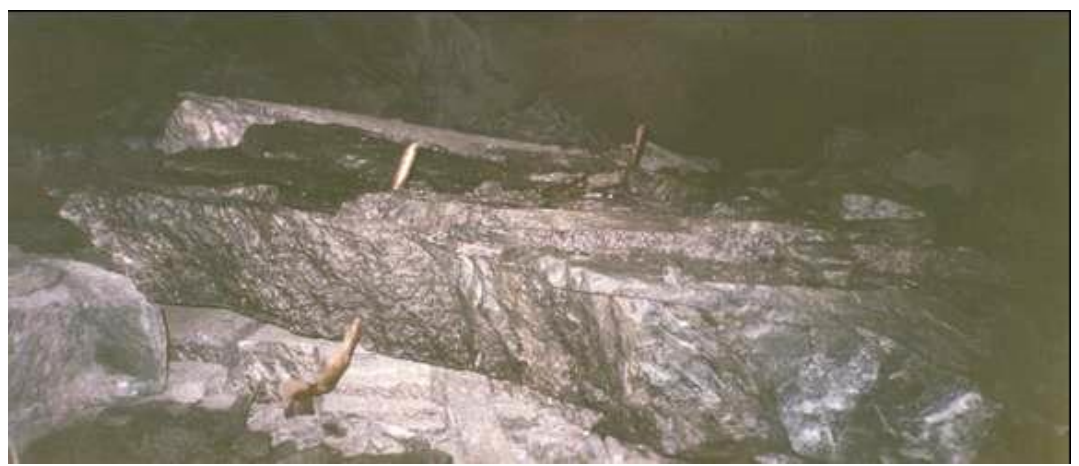

Figure 4 Roof failure caused by over stressing of geological structures

Another difficult situation occurs when low strength zones extend high in the back, and the potential caving area can include an already bolted section and be a serious threat if the extent of the poor ground conditions is not properly evaluated. The presence of local shear structures or low rock mass quality is an indication of a potentially high roof failure. As an example Figure 5 shows a roof failure located around a shear zone, although the visible sheared area was about $1 \mathrm{~m}$ in thickness, the resulting failure area was localised on a $2.5 \mathrm{~m}$ long section reaching over $3 \mathrm{~m}$ above the roof line. After the first roof failure, an extensive review of the geological mapping showed that the sheared and weathered geological structures in this mine were very continuous and extended over several levels, and this situation repeated itself every $20-30 \mathrm{~m}$ on more than nine working levels. A strategy of forepiling with water expanded bolts and split tube bolts was implemented, combined with the use of shotcrete and a small reduction in drift advance, in order to increase the unsupported stand up time to a level where radial bolting and a second pass shotcreting could be performed to finalise the support. The forepiling and $5 \mathrm{~cm}$ shotcrete shell secured the roof long enough to make the development safe.

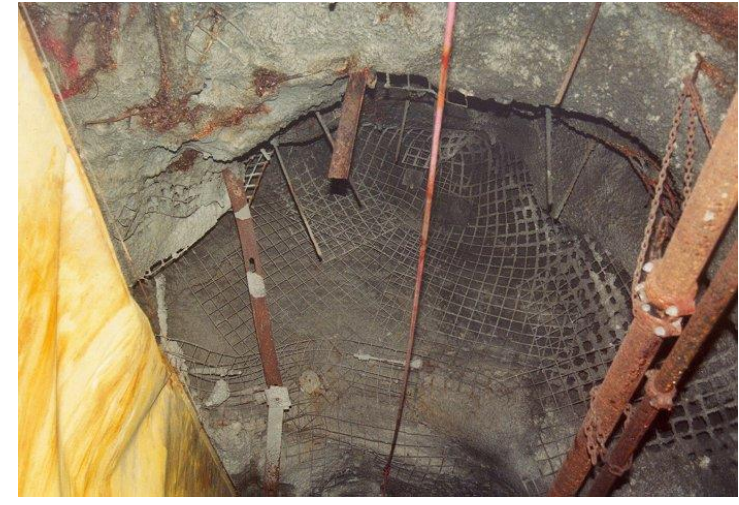

Figure 5 High roof failure following shear zone

\subsection{Corrosion resistance}

The effects of corrosion can be seen in several ways. A direct impact that is obvious is when the rockbolt is corroded rapidly and instability results (Figure 6). A more insidious situation occurs when the rockbolt is slightly corroded in areas of intersecting joints and shear planes, resulting in reduced strength and deformability and lower reinforcement performance. A partly corroded rockbolt will have a lower strength and may be more sensitive to the motion waves of a dynamic event.

Figure 7 presents the results of pull tests performed on water expanded rockbolts over a period of five years, with some bolts being as old as 15 years at the end of the study. The group of mines in which the tests were 
performed had ground conditions that can be considered as mildly corrosive for an industrial site. The spread of pull out load shows the stochastic aspect of the corrosion of rockbolts. It has been observed that not every bolt corrodes at the same rate, and over a period of a few years, this variation will lead to a wide variation of remnant strength. To date, no such database exists for other types of rockbolts. However, it would be quite valuable to be able to link a load probability to a bolt of a given age in known conditions. Low $\mathrm{pH}$ (acidic) conditions are well known to affect adversely any steel component, but other situations involving chloride ions, iron and atmospheric contaminants can also create a surprisingly corrosive combination. Fully grouted bars as well as coated water expanded bolts are best suited for those environments, although a non protected friction bolt or water expanded bolt could perform well in some conditions.

a)

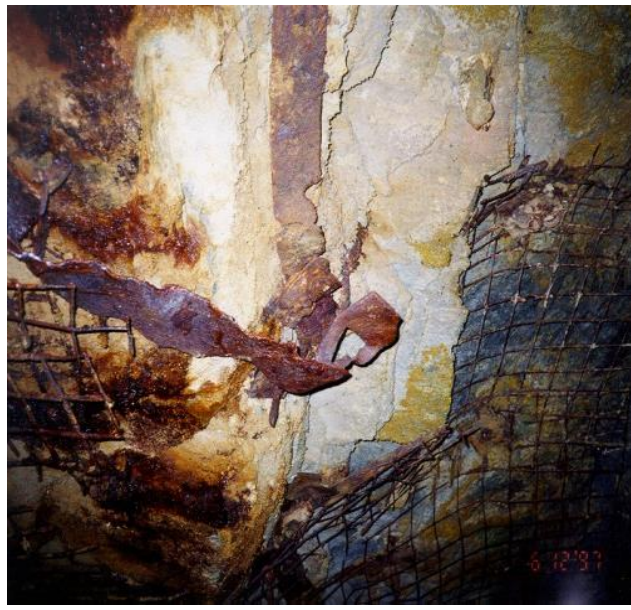

b)

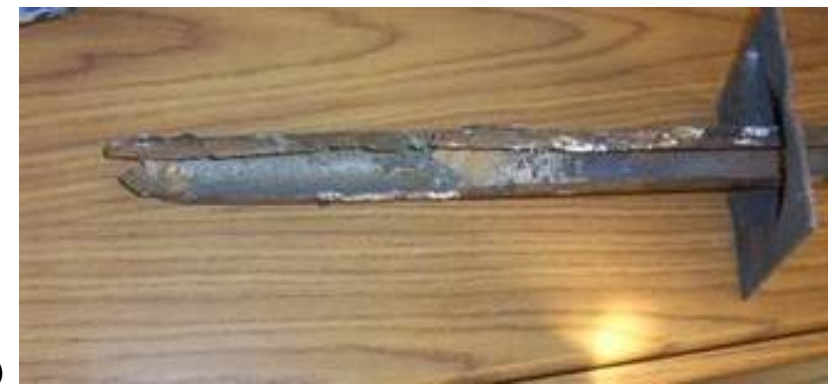

Figure 6 Obvious failure of ground support caused by corrosion: a) wall failure; b) corroded split tube bolt

Capacity versus Time - Group 1

With Corrosion Rates

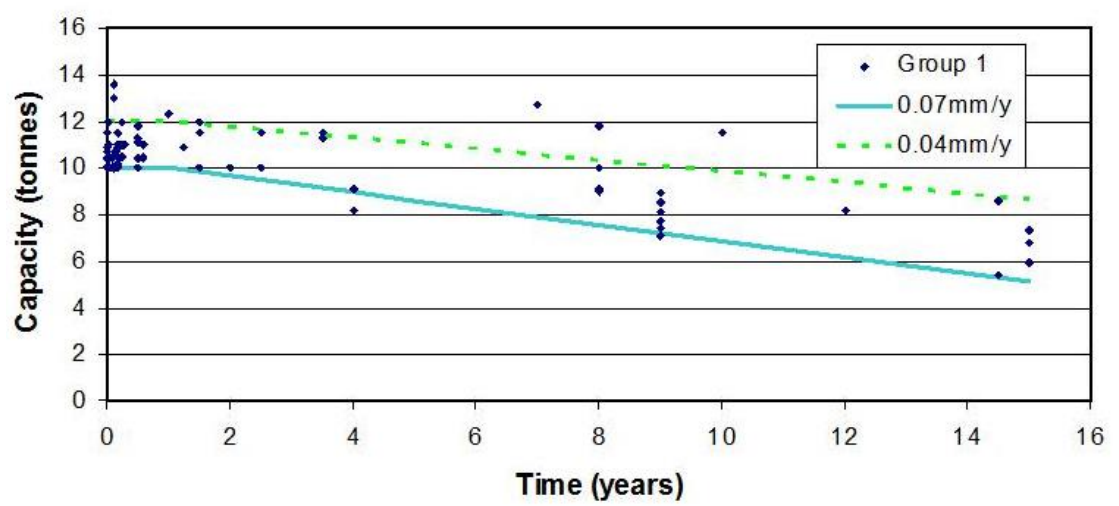

Figure 7 Load capacity at the collar measured by pull out load for water expanded bolts of various age, in mildly corrosive mining environments (Charette et al., 2004)

\subsection{Bolting costs}

A constant challenge associated with mining is the necessity to control the costs of stabilisation of the excavations while providing the right amount of safety for people and equipments. Choosing the right rockbolt type includes a financial justification of the reinforcement operation and the more information available, the better the engineer can make an adequate decision. There are several ways to analyse the bolting performance related with the use of a given rockbolt. Some methods can be very simple, and take into account only the purchasing cost, while others will allow a more complex and realistic view of the bolting process. 
A very crude method is to compare the purchasing cost of the different bolting systems, but given the competitive aspect of the supply business and the differences in the installation methods of each of them, it is not a very reliable method of comparison.

In ground conditions where all rockbolt types under study are adequate, a satisfactory method of analysis is to compare the total cost $/ \mathrm{m}$ related to the material and the bolting operation. Figure 8 is based on field measurements and presents a comparison of five rockbolts used in various mining operations related to mine development. A standard bolting pattern of $1.2 \times 1.2 \mathrm{~m}$ was used and the load capacity of the bolts was not a limiting factor, all of them were deemed sufficient to perform adequately.

Ore Development and Production Cut and Fill

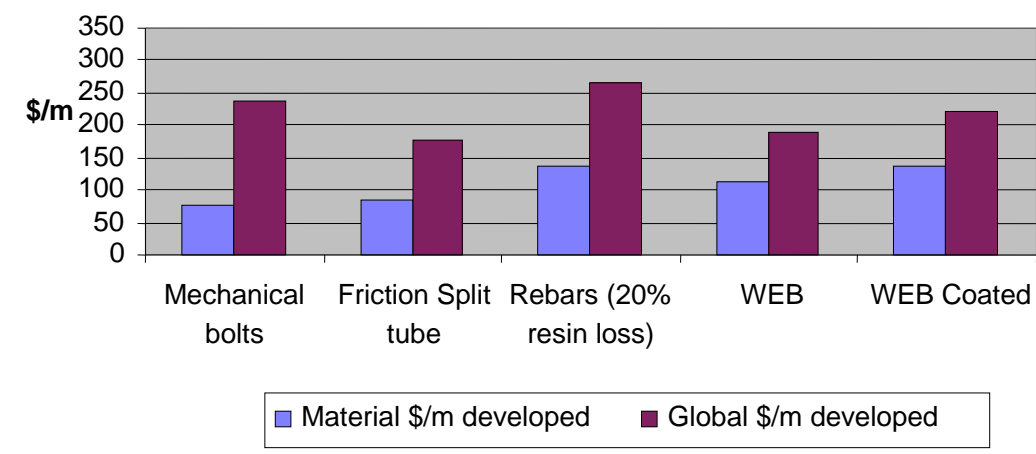
Ore Development and Production
Long Holes Stoping

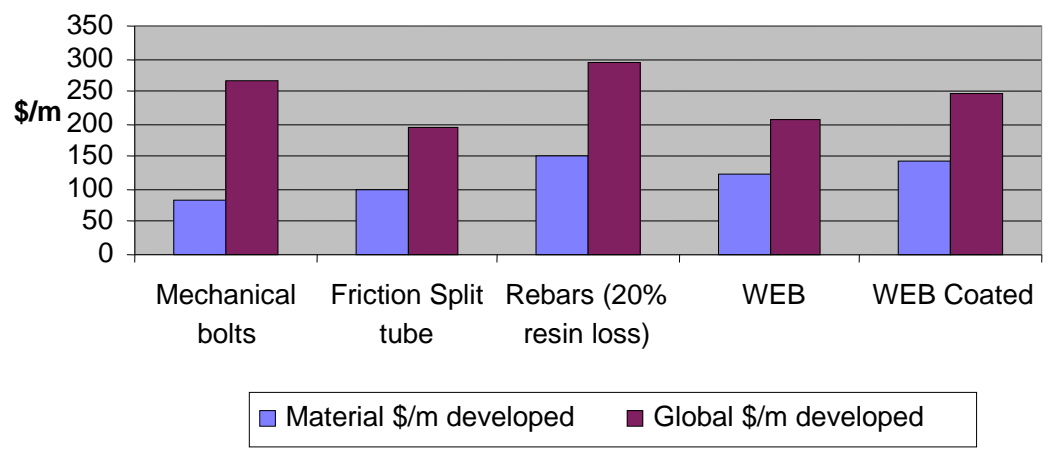

\section{Figure 8 Development costs in $\mathrm{C} \$ / \mathrm{m}$ advance for different bolts and similar bolting patterns}

However, when a minimum support pressure is required, the bolting pattern has to be adapted to meet this support level, and the increase in bolt numbers is a function of the typical load capacity of the bolt type. For example, if a minimum pressure of $69 \mathrm{kN} / \mathrm{m}^{2}$ is required (similar to a $100 \mathrm{kN}$ load over a $1.2 \times 1.2 \mathrm{~m}$ pattern), it will take $20 \%$ more of $80 \mathrm{kN}$ bolts than $100 \mathrm{kN}$ bolts in the same area to provide the same support. Figure 9 modifies the results of Figure 8 in presenting the cost $/ \mathrm{m}$ of various reinforcements providing a $69 \mathrm{kN} / \mathrm{m}^{2}$ support pressure. Also, a similar reduction factor can be used to de-rate the support pressure of a given bolt system based on the difficulty to perform quality control or to take into account the reduction of reinforcement effects caused by a less than ideal installation procedure. 


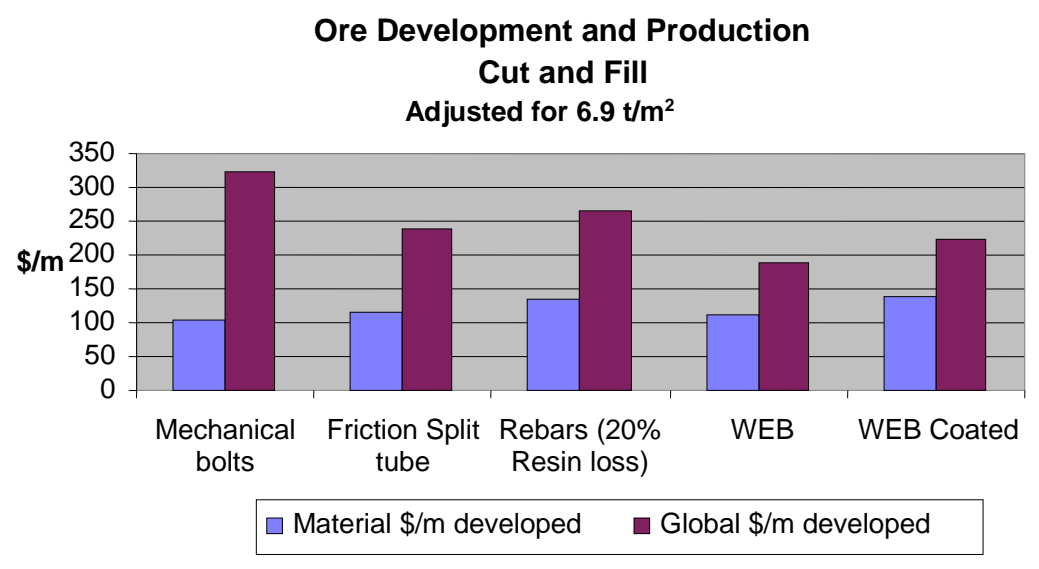

\section{Ore Development and Production Long Holes Stoping Adjusted for $69 \mathrm{kN} / \mathrm{m}^{2}$}

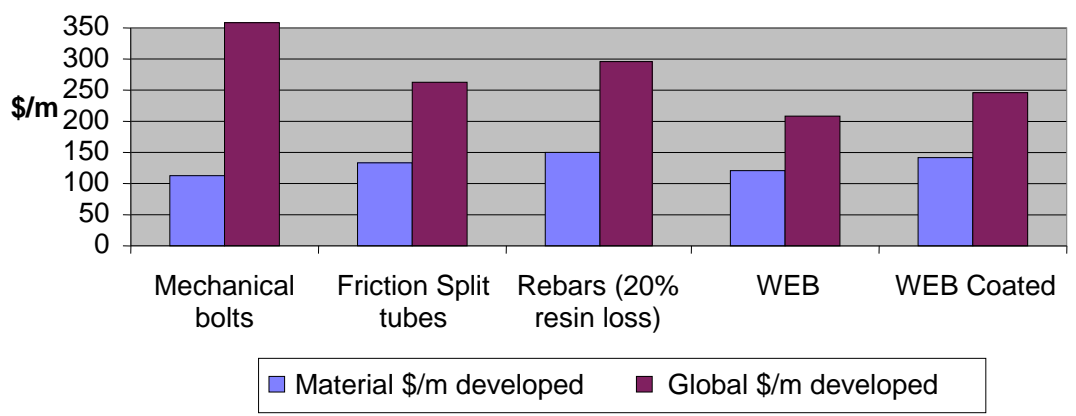

Figure 9 Development costs in $\mathrm{C} \$ / \mathrm{m}$ advance for adjusted bolting patterns to a similar support pressure

Another method of analysis consists in taking into account all phases of the bolting operation. A time study is a very useful tool to adequately compare the performance of bolt types and mechanisation. Figures 10 and 11 present the results of such a study, comparing resin grouted rebars and WEB bolts, for manual and mechanised installation processes. In addition to total installed costs, the performance of advance can also be determined using such a study. 


\section{Time installation per bolt}

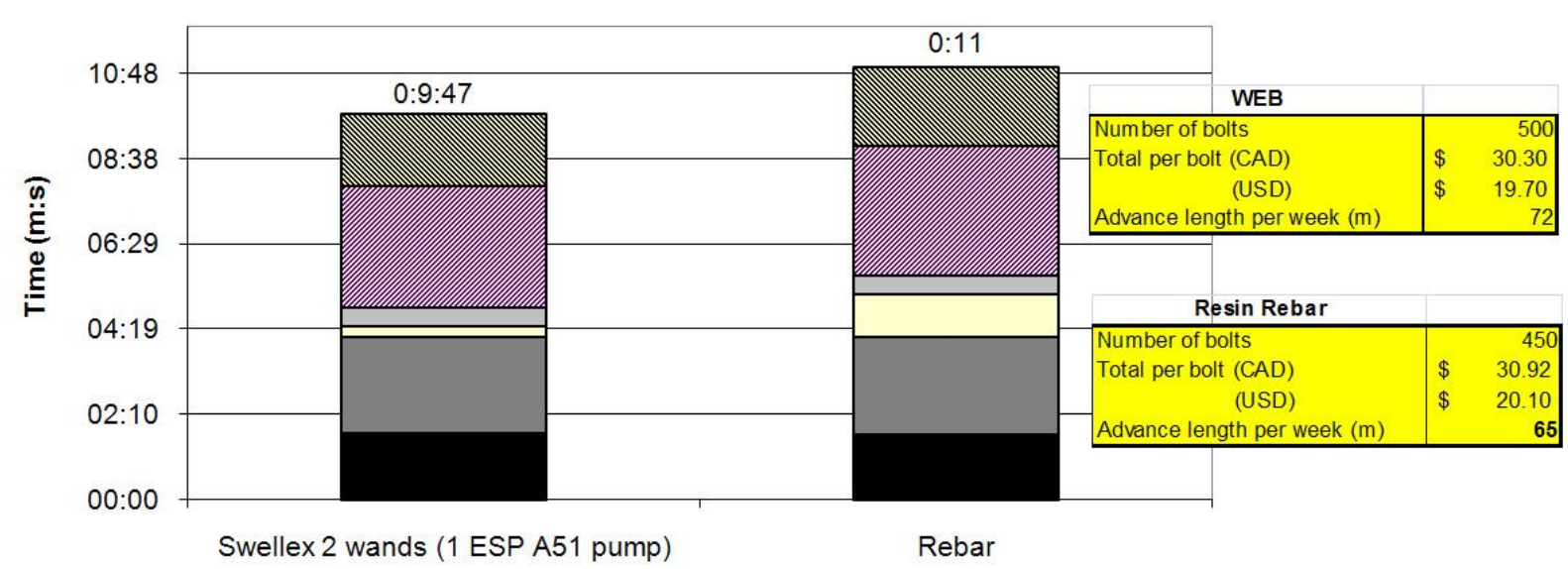

Type of Bolt

\begin{tabular}{|ll|}
\hline Scalling time & $\square$ Drilling time \\
$\square$ Installation time & $\square$ Screen installation time \\
⿴囗Miscellaneous time lost & $\mathbb{B}$ Breakfast and lunch \\
\hline
\end{tabular}

Figure 10 Results of a 2006 time study to compare resin rebars and water expanded rockbolts for manual installation

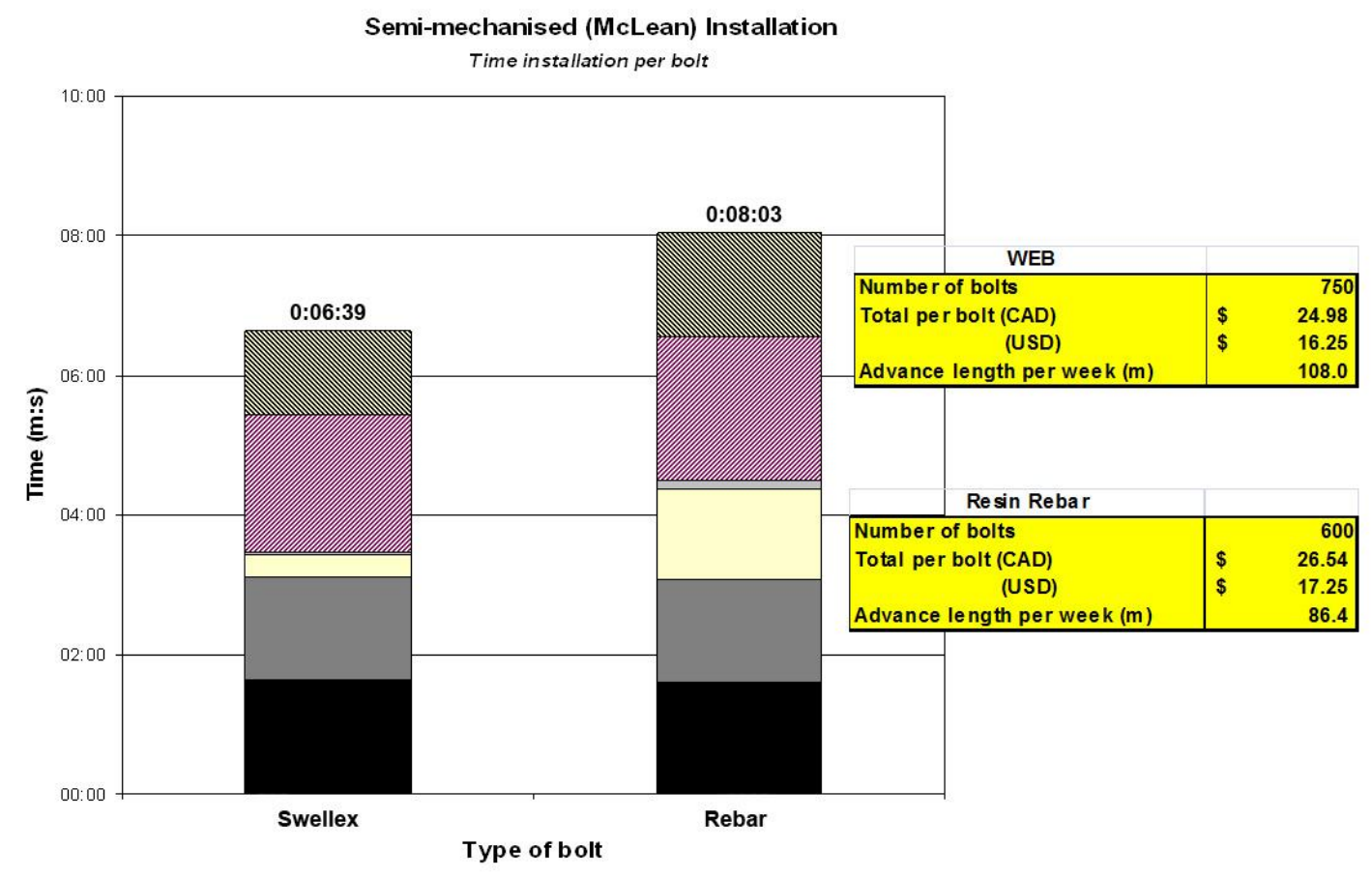

Scalling time

$\square$ Drilling time

$\square$ Installation time

$\square$ Screen installation time Miscellaneous time lost $\mathbb{B}$ Breakfast and lunch

Figure 11 Results of a 2006 time study to compare resin rebars and water expanded rockbolts for installation with a McLean bolting rig 
Data found in Figures 8 to 11 are typical of manual and semi-mechanised bolting operations in underground metal mines in hard rock in Canada. It will be recognised that the lower cost rockbolt is not always the more economical for the whole bolting operation. For example, typical expansion shell anchors lose their tension when the roof is not constantly under stress, or when blasting is performed close by. If the bolts are to be used for systematic reinforcement, they have to be re-tensioned regularly, adding loss of time to the direct cost of re-torquing the bolts. The use of a weaker bolting element may lead to increased material costs (Figure 9), while the use of an over-designed bolting element could add unnecessary costs to the operations. The bolt type and capacity has to suffice for the complete life time requirement of the bolting system.

\subsection{Mechanisation}

Rockbolting is a difficult operation that requires experience and skill from the bolters, and such talents are necessary for both manual and mechanised operations. In a manual bolting operation, the miners are usually in a team of two or three, and utilise scissor trucks to reach the roof and the higher parts of the walls or ribs. With good bolting practices, a bolting crew can safely work its way from the supported area to the nonsupported area. A two man team can work with two drills side by side, staying under supported ground, and achieve a good bolting performance through the use of low costs and low maintenance equipments that are very flexible. By contrast, using a dedicated bolting machine allows having a better bolting performance with only one man, usually in a more secure position. Good scheduling and maintenance operations are necessary to take full advantage of the bolting machine, and when used adequately, a mechanised bolting operation can increase productivity by 30-50\%, depending of the bolt type (Figure 11). Obviously, in bad ground conditions, the use of a fully mechanised bolting machine is a definite advantage on a safety point of view. Also, the ability to safely bolt out of reach areas increases productivity and reduces risks and costs.

Mechanised bolting also has its productivity and safety drawbacks, mainly when the bolting equipment is not well adapted to the task at hand. In a semi-mechanised bolting operation, installation of resin rebars is a process that often brings the operator close to the edge of the platform in order to insert the resin cartridges in the hole. While in fully mechanised bolting with resin grouted rebars, insertion of the cartridges is a hit and miss operation with most bolting systems. Mesh installation is still not a friendly operation with most rockbolting equipment. Cement grout injection could be simplified and automated, resulting in a wider and better use of cementitious materials, reducing waste and costs. These specific aspects of rockbolting have been traditionally avoided by the bolting manufacturers. Scandinavian mining functions without the use of mesh, hence rockbolting equipment is not specifically designed with this in mind. This is rather surprising when it is well known that mesh provides support and confining effects to the rock mass that are quite important to improving rock stability.

\section{Conclusions}

To perform the design of rock support systems, ground engineers have access to a large number of design tools. However, availability of all these methods will not compensate for a lack of common sense. The rapidity and safety of the mine development is dependent on the knowledge and control of the critical factors affecting the stability of the excavations. These factors can be a specific geological structure, ground conditions prone to rockbursting, very acidic groundwater conditions, low in situ stress areas, etc. A suggested procedure for the choice of the support system should include:

- Definition of the general behaviour and failure mode of the rock mass.

- A definition of the main geological structures to evaluate their spatial extension and thickness, and keep their intersection with present and future excavations well documented.

- A sound approach to calculate the needed mechanical properties of the rock support system, for static and dynamic conditions, present and future. In case of medium-strong to very strong rock, or where the extraction rate is high (above $3000 \mathrm{t} /$ day) in a single orebody, the evaluation of energy release rate should be done for various mining strategies, and large increases predicted and investigated more in detail to define the dynamic strength properties necessary.

- Eliminate from the pool of solutions the reinforcement elements that do not perform well in the specific conditions identified. 
- Perform a detailed cost comparison between the acceptable support systems, using a total cost approach that includes: unit costs of support and reinforcement elements, drilling, handling, installation, quality control and rehabilitation costs due to inadequate performance or corrosion.

Table 2 is a suggested matrix to help eliminate the reinforcement types that should not be used. The recommendations listed in the table are drawn from field experience with these rock reinforcement systems in North America most specifically. There is no limit criteria proposed as this can be better defined by the ground control engineer for every specific site. However, the suggested matrix can give some clues to an operator and hence question the use of potentially unsuited reinforcement elements. Ideally, this scheme could be filled with hard numbers referenced with underground stability and instability cases, to provide a framework for a better choice of reinforcement. Figure 12, from Heal and Potvin (2007), presents a very good example of quantitative comparison leading to a sound selection of a support system.

It must also be realised that, once a support system is implemented, it is very costly to modify, if it proves to be inadequate. In the case of Figure 3, the cost was quite significant. It was not possible to recognise the stress related events that lead to a $10 \mathrm{t}$ rockfall. Small ground falls were attributed to possibly corroded roof bolts, although the observed corrosion intensity did not match the seemingly small carrying load of the bolts. Roof support, consisting of water expanded bolts and cable bolts (Figure 3), did provide for a safety factor of over 16 with six water expanded bolts and two double cables, but did not succeed in preventing this failure. Dynamic loads can exceed by more than 20 times the static load if no sliding of the anchor occurs, and although the support was working adequately, it was not designed for the dynamic situation. Figure 13 shows a similar example of a design where the support capacity was not well matched with the load demand of the ground conditions, in this case strain bursting conditions.

\section{Table 2 Recommendations for selection of reinforcement type}

\begin{tabular}{|c|c|c|c|c|c|c|}
\hline \multirow{3}{*}{$\begin{array}{l}\text { Rockbolt } \\
\text { Types }\end{array}$} & \multicolumn{6}{|c|}{ Ground Conditions } \\
\hline & \multicolumn{2}{|c|}{ Hard Rock } & \multicolumn{2}{|c|}{$\begin{array}{c}\text { Hard } \\
\text { Laminated } \\
\text { Rock }\end{array}$} & \multirow{2}{*}{$\begin{array}{l}\text { Soft-Medium } \\
\text { Rock } \\
\text { Laminated or } \\
\text { Not }\end{array}$} & \multirow[t]{2}{*}{$\begin{array}{c}\text { Very Soft Rock } \\
\text { Broken } \\
\text { Ground }\end{array}$} \\
\hline & $\begin{array}{l}\text { High } \\
\text { Stress }\end{array}$ & $\begin{array}{l}\text { Low } \\
\text { Stress }\end{array}$ & $\begin{array}{l}\text { Low } \\
\text { Stress }\end{array}$ & $\begin{array}{l}\text { High } \\
\text { Stress }\end{array}$ & & \\
\hline $\begin{array}{l}\text { Expansion } \\
\text { anchor }\end{array}$ & $\mathrm{N}$ & A & $\mathrm{A}$ & $\mathrm{N}$ & $\mathrm{N}$ & $\mathrm{N}$ \\
\hline Split tube & A & $\mathrm{A}$ & $\mathrm{A}$ & A & $\mathrm{A}$ & A (walls) \\
\hline Grouted rebar & $S$ & S & S & A & $S$ & A \\
\hline $\begin{array}{l}\text { Water } \\
\text { expanded } \\
\text { tube }\end{array}$ & $\mathrm{N}$ & A & A & $\mathrm{N}$ & $S$ & $S$ \\
\hline $\begin{array}{l}\text { Fibreglass } \\
\text { dowels }\end{array}$ & $\mathrm{N}$ & A & A & $\mathrm{N}$ & $S$ & A \\
\hline $\begin{array}{l}\text { Yielding } \\
\text { bolt/cables }\end{array}$ & S & S & S & $S$ & S & $\mathrm{S}$ \\
\hline
\end{tabular}




\section{Comparison of Ground Support Systems}

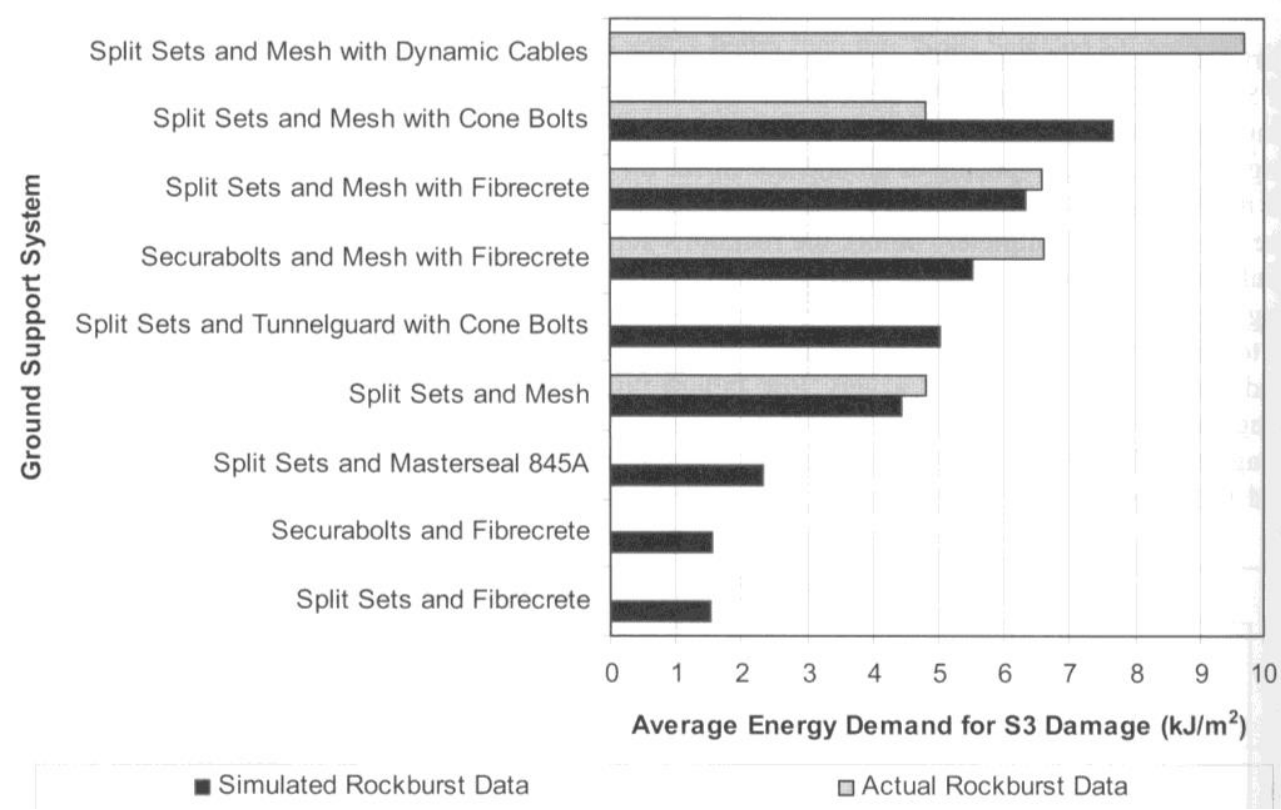

Figure 12 Comparison of ground support systems based on their ability to resist dynamic loading conditions (Heal and Potvin, 2007)

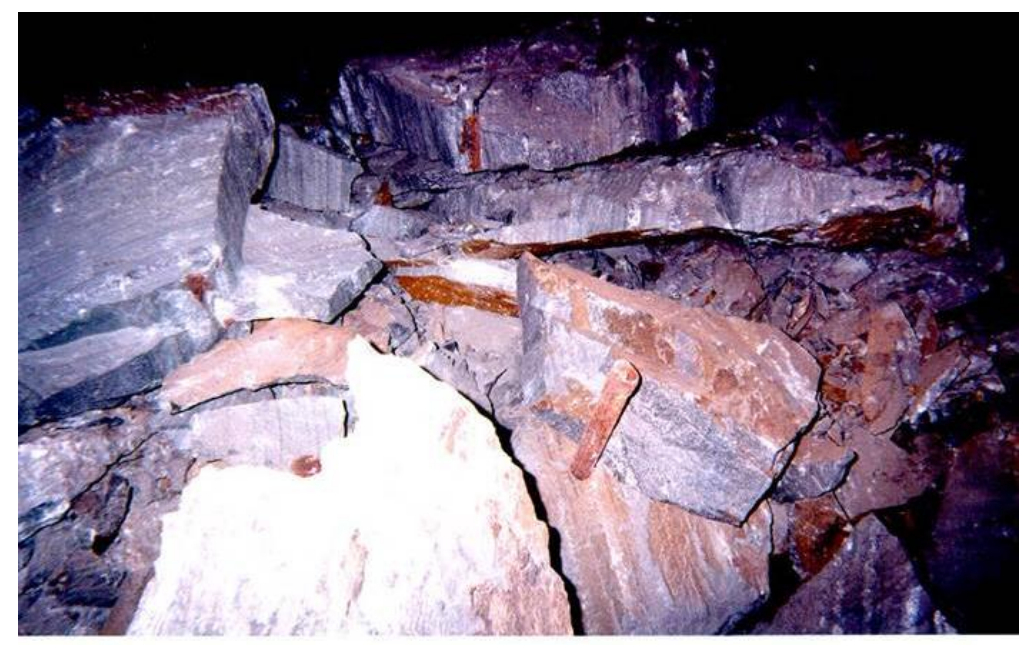

Figure 13 Roof and support system failure caused by dynamic loading

\section{References}

Barton, N., Lien, R. and Lunde, J. (1974) Engineering classification of rock masses for the design of tunnel support. Rock Mechanics, Vol. 6. No. 4, pp.189-236.

Charette, F., Germain, P. and Hadjigeorgiou, J. (2004) Corrosion Behaviour of Swellex Bolts in Underground Mining Environments, 106th CIM Annual General Meeting.

Diederichs, M.S., Espley, S. and Langille, C. (1998) Optimizing Support Design for Wedge Instability — The Viability Index, 100th CIM Annual General Meeting, CD-Rom, Montréal, pp. 1-8.

Heal, D. and Potvin, Y. (2007) In-situ testing of ground support using simulated rockbursts, Proceedings of the Fourth International Seminar on Deep and High Stress Mining, Potvin (ed), Australian Centre for Geomechanics, Perth, Australia, pp. 373-394.

Hoek, E., Kaiser, P.K. and Bawden, W.F. (1995) Support of Underground Excavations in Hard Rock, A.A. Balkema, Rotterdam, $215 \mathrm{p}$

Hutchinson, D.J. and Diederichs, M. (1996) Cable bolting in Underground Mines, BiTech Publishers, Richmond, 406 p. 